Olutomi I. Adeyemi, David C. Broadstock, Mona Chitnis, Lester C. Hunt and Guy Judge (2010), "Asymmetric Price Responses and the Underlying Energy Demand Trend: Are they Substitutes or Complements? Evidence from Modelling OECD Aggregate Energy Demand", Energy Economics, Vol. 32, No. 5, pp. 1157-1164.

\title{
Asymmetric Price Responses and the Underlying Energy Demand Trend: Are they Substitutes or Complements? Evidence from Modelling OECD Aggregate Energy Demand
}

\author{
Olutomi I Adeyemi ${ }^{a}$, David C Broadstock ${ }^{a}$, Mona Chitnis ${ }^{a, b}$, \\ Lester C Hunt ${ }^{a, b, *}$ and Guy Judge ${ }^{a, c}$ \\ a Surrey Energy Economics Centre (SEEC), University of Surrey, UK. \\ ${ }^{b}$ Research Group on Lifestyles Values and Environment (RESOLVE), University of Surrey, UK. \\ ${ }^{c}$ Department of Economics, University of Portsmouth, UK. \\ * Corresponding Author: Surrey Energy Economics Centre (SEEC), Department of Economics, \\ University of Surrey, Guildford, Surrey, GU2 7XH \\ Tel: +44(0)1483 686956, Fax: +44(0)1483 689548, Email: L.Hunt@surrey.ac.uk
}

\begin{abstract}
A number of energy demand studies have considered the importance of modelling Asymmetric Price Responses (APR), for example, the often-cited work of Gately and Huntington (2002). Griffin and Schulman (2005) questioned the asymmetric approach arguing that this is only capturing energy saving technical progress. Huntington (2006), however, showed that for whole economy aggregate energy and oil demand there is a role statistically for both APR and exogenous energy saving technical change.

In a separate strand of the literature the idea of the Underlying Energy Demand Trend (UEDT) has been developed, see for example Hunt et al. (2003a and 2003b) and Dimitropoulos et al. (2005). They argue that it is important, in time series energy demand models, to allow for stochastic trends (or UEDTs) based upon the structural time series/dynamic regression methodology recommended by Harvey $(1989,1997)$.

This paper attempts to bring these strands of the literature together by proposing a testing procedure for the UEDT and APR in energy demand models within both a panel context (consistent with the Huntington, 2006 approach) and the structural time series modelling framework. A set of tests across a range of specifications using time-series and panel data are therefore suggested in order to ascertain whether energy saving technical change (or the more general UEDT) and APR are substitutes for each other when modelling energy demand or whether they are actually picking up different influences and are therefore complements.

Using annual whole economy data for 17 OECD countries over the period 1960 - 2006 the results suggest that for most of the countries the UEDT is preferred to APR, whereas for another group the UEDT and APR are complements, and for another group they are substitutes. It is argued therefore that energy demand modellers should not assume at the outset that one method is superior to the other. Moreover, wherever possible, a general model (be it in a time series or panel context) that includes a 'non linear UEDT' and APR should be initially estimated, and only if accepted by the data should symmetry and/or a more restrictive UEDT be imposed.
\end{abstract}

Key Words: Energy Demand, OECD, Asymmetric Price Responses, Underlying Energy Demand Trend.

JEL Classifications: C22, C23, C52, Q41. 


\section{Acknowledgements}

The authors are grateful for the insightful comments by two referees on an initial draft of the paper and thank them for helping to improve the paper in many places. The authors are also grateful for the comments on earlier drafts of the work presented at: the Centre for Energy Policy and Economics (cepe) Seminar, Zurich Institute of Technology, Switzerland, January 2005; the $5^{\text {th }}$ BIEE/UKERC Academic Conference, Oxford University, UK, September 2005; and $9^{\text {th }}$ IAEE European Conference, Florence, Italy, June 2007. Of course, any errors and omissions are due to the authors. 


\section{Introduction}

Energy demand models are often developed on the premise (or more appropriately on the assumption) that consumer behaviour is defined by symmetric responses to rising or falling prices and income, recent examples being Ahmadian et al. (2007) and Lescaroux and Rech (2008). It is equally plausible, however, that consumers might react differently to price rises than they would to price falls, be it because of habit formation, the desire to improve life quality or any other reason. Consequently, asymmetric price decompositions have found increasing use in the energy demand literature, see for example, Dargay (1992), Dargay and Gately (1995a, 1995b and 1997), Gately (1993), Gately and Huntington (2002), Griffin and Schulman (2005), Ryan and Plourde (2002) and Adeyemi and Hunt (2007). ${ }^{1}$

An influential and often quoted paper by Gately and Huntington (2002) eloquently demonstrates why, and how, consumers of energy will respond differently to, not only price cuts and price rises, but importantly also to price rises above the previous maximum and price recoveries below the previous maximum. ${ }^{2}$ Furthermore, using panel data and a Koyck lag model they provide empirical estimates for OECD and Non-OECD energy and oil demand, showing that asymmetric price responses, achieved by decomposing the price variable, are very often accepted by the data.

Griffin and Schulman (2005), however, argue that the price asymmetry methodology adopted by Gately and Huntington (2002) is really only acting as a proxy for energy-saving technical

\footnotetext{
${ }^{1}$ Although it should be noted, this is not an exhaustive list, with a number of other papers also addressing the issue of asymmetry when modelling energy demand.

${ }^{2}$ In fact, Gately and Huntington (2002) also demonstrate that this might also apply to changes in economic activity; however, overall symmetry for the income responses is generally favoured over asymmetry. This is ignored in this paper since the discussion focuses on asymmetric price responses and underlying exogenous energy saving trends, although the Huntington (2006) asymmetry tests within a panel context and the further tests utilised in this paper in a time series context could equally be applied to testing for the asymmetry of an economic activity variable.
} 
change. They therefore included time dummies as a proxy for technical progress both in symmetric and asymmetric price response models for OECD energy (and oil) demand, concluding that they "prefer a simple symmetric price specification that separately accounts for technical change via time dummies in a panel data model" (p. 19). In his response, Huntington (2006) formally tests the restrictions of symmetry and no time dummies in the Griffin and Schulman (2005) models and finds that statistically the restrictions are not accepted by the data, arguably showing that in explaining past OECD energy (and oil) demand both asymmetric price responses and the exogenous time dummies might have a role to play. Adeyemi and Hunt (2007) further explored these ideas for OECD Industrial Energy Demand also using a Koyck lag model in a panel context. They also found that from a statistical perspective asymmetric price responses and the exogenous time dummies both have a role to play, but given individual coefficient values and level of significance led them to conclude that the asymmetric model without time dummies is to be preferred for "pragmatic reasons" (p. 706). Nevertheless Adeyemi and Hunt (2007) conclude that their "exercise shows that when estimating energy demand models and considering the important issue of energy-saving technical progress (and other exogenous trends) a general flexible approach should initially be adopted" and that the "chosen model should be the one that is accepted by the data while the same time conforming to economic theory - but this should be estimated and tested rather than imposed at the outset" (p. 706). ${ }^{3}$

The above illustrates the debate in the energy demand literature concerning asymmetry, in particular in a panel context, and in their conclusion Griffin and Schulman (2005) state that in future research it is "imperative that we understand the extent to which technical change is neutral or price-induced" (p. 19). This paper therefore uses the tests undertaken by

\footnotetext{
${ }^{3}$ Furthermore, Adeyemi and Hunt (2007) highlight a number of lines of future research that are undertaken in this paper, albeit at the whole economy level, rather than for the industrial sector.
} 
Huntington (2006) to help understand, when modelling energy demand, whether a specification with Asymmetric Price Responses (APR) can be regarded as a substitute or complement for 'exogenous energy saving technical change via time dummies'.

The above is very 'panel data specific'. An attempt is made here therefore to link this to, and develop analogous tests for, a separate strand of the energy demand modelling literature; i.e. what is the most appropriate way to account for technical progress when modelling energy demand using time series data. For a long while, the most common way to try to capture the technical progress of the appliance and capital stock was by the inclusion of a simple deterministic time trend. Although there were arguments against this (see Kouris 1983a and 1983b for example), it was seen by many (see Beenstock and Willcocks 1981 and 1983 for example) as the best procedure available given the lack of any feasible alternative. ${ }^{4}$

More recently Hunt et al. (2003a, 2003b), Hunt and Ninomiya (2003) and Dimitropoulos et al. (2005) have argued that, given the advances in Structural Time Series Modelling (STSM), see Harvey $(1989,1997)$, a stochastic trend, entitled the Underlying Energy Demand Trend (UEDT), should be incorporated in any initial general time series model of energy demand. Moreover, the UEDT captures not only exogenous technical progress (or energy saving technical change) but other important socio-economic effects (see Hunt and Ninomiya, $2003)^{5}$

One potential problem with this approach however, is that arguably the estimated UEDTs may just be a proxy for APR, so what is essentially a price induced asymmetric response is captured as an exogenous effect given that the specification only allows for symmetric price

\footnotetext{
${ }^{4}$ This debate is considered in full in Hunt et al. (2003a and 2003b).

${ }^{5}$ Discussion on how the STSM method is used to derive the UEDT is given in the methodology section below.
} 
responses. This is therefore seen as similar to the issue raised by Griffin and Schulman (2005) who conversely argued that, in a panel context, APR just proxy energy saving technical progress whereas for a time series model the stochastic UEDT could arguably proxy APR. Furthermore, the estimated coefficients for the time dummies in a panel model are likely to have a 'non-linear' shape with periods where they increase and other periods where they decrease (see the example from Griffin and Schulman, 2005 in Figure 1a) - similar to the non-linear estimated UEDTs in a time series model (see the example from Dimitropoulos et al. 2005 in Figure 1b). In fact, it could be argued that Figure 1 appears to show that the general decline in the estimated UEDTs, in particular from the panel estimation, are interrupted at precisely the same time as major price shocks - perhaps visually suggesting some form of complementarity between the two factors - hence further reason for the need to test econometrically.

\section{\{Insert Figure 1 about here\}}

In summary, there is a need to try to determine whether APR (in both panel and time series models) or the UEDT (estimated via time dummies in panel models or a stochastic trend in time series models) are preferred to each other or whether both schools of thought have a role to play. In other words, as stated above, are they substitutes or complements when modelling energy demand?

The remainder of the paper attempts to set up a testing procedure to try and help answer this question for aggregate energy demand using a sample of 17 OECD countries over the period 1960 to 2006 . The next section discusses the philosophy and methodology of the testing 
procedure. Section 4 provides a brief overview of the data and presents the results. A summary and conclusion is given in Section 5 .

\section{Testing philosophy and methodology}

The testing philosophy utilised here is underpinned by the 'general-to-specific' modelling school of thought in that general unrestricted models are initially hypothesised with restrictions of symmetry or no UEDT imposed and tested both in a time series and panel data context. The tests may be thought of as either testing whether there is a role to play for a UEDT in a model that incorporates asymmetric price responses (denoted Test 1 below) or testing whether there is a role to play for APR in a model that incorporates a UEDT (denoted Test 2 below). ${ }^{6}$ In other words, the intention is to provide a testing framework that helps clarify whether the UEDT and APR are substitutes or complements. To do this it is assumed that the UEDT is modelled using time dummies in a panel data context (as advocated by Griffin and Schulman, 2005) or by a stochastic trend in a time series context (as advocated in Hunt et al. 2003a and 2003b). Moreover, APR are modelled in both a panel context and a time series context using the decomposition of the price variable explained below (as advocated in Gately and Huntington, 2002, for example).

Given the framework adopted, a number of different models are tested. For the time series data it includes a 'static' model, a 'partial adjustment model' (or 'PAM') and an 'Autoregressive Distributed Lag Model with a lag of one year' (or 'ARDL"7 given an ARDL

\footnotetext{
${ }^{6}$ Note that in the main text, given the emphasis in the literature it is assumed that there is a role to play for at least one of these in the general model. However, the Appendix presents the tests for whether there is a role for either a model of asymmetric price responses or a UEDT in a model with a symmetric model with no UEDT and in general shows that there is.

${ }^{7}$ Technically this is ARDL(1,1) given there is a one year lag on the autoregressive and distributed lag components but ARDL is used for short hereafter.
} 
model is used by Hunt et al. (2003b), Hunt and Ninomiya (2003) and Dimitropoulos et al. (2005). For the panel data, this includes a 'static' model, a 'PAM' and a 'Koyck' lag model given its popularity, following Gately and Huntington (2002). These specifications are chosen because they have been used in a number of previous papers, but more importantly to ensure that the results of the tests are not 'specification dependent'. 8 Table 1 therefore details Test 1 and Test 2 in a time series context and Table 2 details Test 1 and Test 2 in a panel data context (based upon the tests in Huntington, 2006).

\section{Time Series Data Tests}

The time series tests are undertaken using Harvey's (1989) STSM, which allows for the estimation of a stochastic trend denoted by $\mu_{t}$ (rather than the constant $\mu$ ). Equations (1a), (1b), and (1c) in Table 1 represent the unrestricted models for the three different specifications ('static', 'PAM' and 'ARDL') for Test 1 , where $e_{\mathrm{t}}$ is the natural logarithm of energy consumption per capita $\left(E_{t}\right)$ and $y_{t}$ is the natural logarithm of GDP per capita $\left(Y_{t}\right)$ for each country. $p_{t}^{m}, p_{t}^{r}$ and $p_{t}^{c}$ represent the decomposition of $p_{t}$, the natural logarithm of the real price of energy $\left(P_{t}\right)$ defined, following Gately and Huntington (2002), as the 'cumulative increase in the log of the maximum historical real energy price', 'cumulative sub maximum increase in log of the real energy price', and the 'cumulative decrease in log of real energy price', respectively. ${ }^{9}$

\section{\{Insert Table 1 about here\}}

\footnotetext{
${ }^{8}$ Of course, different specifications could have been chosen, but as stated, the common specifications used in the energy demand literature have been used for comparison, such as the Koyck lag on prices only and not on income, as used by Gately and Huntington (2002). However, the testing philosophy, advocated here, could equally be applied to other specifications.

${ }^{9}$ See Gately and Huntington (2002) for more details.
} 
$\varepsilon_{t}$ is a random white noise disturbance term, $\varepsilon_{t} \sim N I D\left(0, \sigma_{\varepsilon}^{2}\right)$ and $\mu_{t}$, is the stochastic trend which in its general form is assumed to have the following stochastic process:

$$
\begin{array}{ll}
\mu_{t}=\mu_{t-1}+\alpha_{t-1}+\eta_{t} & \eta_{t} \sim \operatorname{NID}\left(0, \sigma_{\eta}^{2}\right) \\
\alpha_{t}=\alpha_{t-1}+\xi_{t} & \xi_{t} \sim \operatorname{NID}\left(0, \sigma_{\xi}^{2}\right)
\end{array}
$$

The trend includes a level component, equation (4a), and a slope component, equation (4b), with its nature dependent upon the variances $\sigma_{\eta}^{2}$ and $\sigma_{\xi}^{2}$, known as hyperparameters so that it can be either linear or non-linear depending on whether the hyperparameters are zero or not. However, in order to ensure that the analysis is tractable and aid exposition of the testing procedure the slope component of the trend is omitted here so the simpler representation is given by:

$$
\mu_{t}=\mu_{t-1}+\eta_{t} \quad \eta_{t} \sim \operatorname{NID}\left(0, \sigma_{\eta}^{2}\right)
$$

so that the stochastic trend is specified when the hyperparameter $\sigma_{\eta}^{2} \neq 0 .{ }^{10}$ The unrestricted models for the three specifications are therefore represented by equations (1a) and (5), equations (1b) and (5), and equations (1c) and (5) respectively. ${ }^{11}$

As illustrated in Table 1 , Test 1 (a likelihood ratio test ${ }^{12}$ ) imposes the null hypothesis restriction that the variance of the trend term is equal to zero so that $\mu_{t}=\mu_{t-1}=\mu$, which is

\footnotetext{
${ }^{10}$ I.e. it is assumed that: $\sigma_{\xi}^{2}=\alpha=0$.
}

It is worth noting therefore, that this allows for less 'variation' in the source of the stochastic trend than the more general specification given by equations (4a) and (4b) so the tests are arguably slightly biased against the acceptance of a stochastic trend.

${ }^{11}$ The STSM is estimated via maximum likelihood in conjunction with a Kalman filter using the software STAMP 6.3 (Koopman et al. 2000).

12 The estimation is undertaken in STAMP 6.3 and, given the restrictions are on the hyperparameters, a likelihood ratio (LR) test is used:

$$
L R_{(r)}=-2\left(L L_{R}-L L_{U}\right) \sim \chi_{r}^{2}
$$

where $L L_{U}$ is the log-likelihood value for the unrestricted model, $L L_{R}$ is the log-likelihood value for the restricted model, and $r$ the number of restrictions on the hyperparameters. 
constant and hence there is no trend, given by equations (2a), (2b) and (2c) for the three specifications respectively. This test therefore maintains APR and tests to see whether there is a role for the stochastic UEDT. If the null is accepted, it suggests that there is no role and hence asymmetry 'dominates' the UEDT; whereas if the null is rejected there is a role for the UEDT suggesting that APR and the UEDT are complements.

As also shown in Table 1, Test 2 (an F-test) imposes the null hypothesis restriction that the coefficients on the decomposed price terms are equal so that there are no APR. ${ }^{13}$ Test 2 therefore maintains the UEDT and tests to see whether there is a role for APR given by equations (3a), (3b) and (3c) with equation (5). If the null is accepted, then there is no role and hence the UEDT 'dominates' APR, whereas if the null is rejected there is a role for APR suggesting that the UEDT and asymmetry are complements.

\section{Panel Data Tests}

The panel data tests are estimated using least squares estimation (either linear or non-linear depending on the specification). ${ }^{14}$ Equations (6a), (6b), and (6c) in Table 2 represent the unrestricted models for the three different specifications ('static', 'PAM' and 'Koyck'15), where the variable definitions are those given above, but now in a panel data context: $e_{i t}, y_{i t}$, $p_{i t}, p_{i t}^{m}, p_{i t}^{r}$ and $p_{i t}^{c}$. Like the time series counterparts these include asymmetric price

\footnotetext{
${ }^{13}$ Again the estimation is undertaken in STAMP 6.3 but, given the linear restrictions are on the parameters, an F-Test is used:$$
F_{\left(r, d f_{U}\right)}=\frac{\left(R_{U}^{2}-R_{R}^{2}\right) / r}{\left(1-R_{U}^{2}\right) / n-k}
$$

where $R_{U}^{2}$ is $R^{2}$ from the unrestricted model, $R_{R}^{2}$ is $R^{2}$ from the restricted model, $r$ the number of linear restrictions, and $d f_{U}$ the degrees of freedom from the unrestricted model.

${ }^{14}$ Estimated and tests undertaken in EViews 7 (2007)

${ }^{15}$ Details of the derivation of this model may be found in Gately and Huntington (2002) or Adeyemi and Hunt (2007).
} 
responses but now allow for country fixed effects via the dummy variables, $D_{i}$ and $\varepsilon_{i t}$ is a random white noise disturbance term; $\varepsilon_{i t} \sim N I D\left(0, \sigma_{\varepsilon}^{2}\right)$. The UEDT is represented by the time dummies, $D_{t}$, following the arguments of Griffin and Schulman (2005) about energy saving technical change.

Test 1 in a panel context is the F-test of linear restrictions advocated by Huntington (2006). As shown in Table 2, this imposes the null hypothesis restriction that the coefficients on the time dummies are equal to zero, thus there is no fixed time effect, given by equations (7a), (7b) and (7c). Thus, analogous to the Test 1 in a time series context, this test maintains APR and tests to see whether there is a role for the UEDT represented by the time dummies. If the null is accepted, it suggests that there is no role and hence APR 'dominate' the UEDT; whereas if the null is rejected there is a role for the UEDT suggesting that APR and the UEDT are complements.

\section{\{Insert Table 2 about here\}}

Test 2 in a panel data context, also advocated by Huntington (2006), is again an F-test of linear restrictions. As also shown in Table 2, this imposes the null hypothesis restriction that the coefficients on the decomposed price terms are equal; hence, there are no APR given by equations $(8 \mathrm{a}),(8 \mathrm{~b})$ and $(8 \mathrm{c})$. Test 2 therefore maintains the UEDT represented by the time dummies, and tests to see whether there is a role for an APR. If the null is accepted, then there is no role and hence the UEDT 'dominates' asymmetry; whereas if the null is rejected there is a role for APR, suggesting that the UEDT and asymmetry are complements. 
With the general testing procedure now in place, the following section presents and discusses the results from implementing the tests. ${ }^{16}$

\section{Data and Results}

The annual data set covers the period 1960-2006 for 17 OECD countries: Austria, Belgium, Canada, Denmark, France, Greece, Ireland, Italy, Japan, Netherlands, Norway, Portugal, Spain, Sweden, Switzerland, the UK, and the US. ${ }^{17}$ The primary source of these data is the International Energy Agency (IEA) database Energy Statistics of OECD Countries available at www.iea.org. This includes each country's aggregate energy consumption in thousand tonnes of oil equivalent (ktoe) and economic activity defined as GDP in billion 2000 US\$ using PPPs over the whole period 1960-2006, both converted to per capita terms, denoted as $E$ and $Y$ respectively.

The index of real energy prices $(2000=100)$ is also taken from the IEA database, but is only for the period $1978-2006$. Consequently this is spliced with an aggregate real price index for each country derived from data in Baade (1981); calculated by weighting gas in households and industry, coal in households and industry, electricity in households and industry, gasoline, diesel fuel and kerosene by their fuel consumption shares. This produces a real aggregate energy price index for each country in 1972 prices $(1972=100)$ over the period 1960 to 1980 . The two series $(1960-1980 ; 1972=100)$ and $(1978-2006 ; 2000=100)$ are subsequently spliced using the ratio from the overlap year 1978 to obtain the real energy price index, denoted by $P$, for each country over the whole period 1960 to 2006 at 2000

\footnotetext{
${ }^{16}$ It should be noted, that the intention here is to develop a general testing procedure to attempt to determine the roles of an APR and a UEDT; estimates of the actual functions will be part of further research.

${ }^{17}$ Further discussion of the data may be found in Al-Rabbaie and Hunt (2006) where a similar data set is used.
} 
prices $(2000=100)$. The natural logarithm of the real energy price, $p$, being decomposed into $p^{m}, p^{r}$ and $p^{c}$ as discussed above.

The results of the estimation procedure are summarised in Table $3 .{ }^{18}$ This presents the probability values (or p-values) for Test 1 and Test 2 applied to the three specifications for time series estimates for each country individually and the 17 countries as a panel. In addition, based on a 5\% significance level, the final three columns indicate whether the null hypothesis is rejected or accepted by ticks and crosses.

- A cross $(\mathrm{X})$ denotes that the null hypothesis is rejected indicating that:

- either adding the UEDT to an asymmetric specification improves the model (Test 1);

- or adding APR to a symmetric model with a UEDT improves the model (Test 2).

- A tick $(\sqrt{ })$ denotes that the null hypothesis is unable to be rejected indicating that:

- $\quad$ either adding a UEDT to an asymmetric specification does not improve the model (Test 1);

- or adding APR to a symmetric model with a UEDT does not improve the model (Test 2).

\section{\{Insert Table 3 about here\}}

\footnotetext{
${ }^{18}$ Given the focus of this paper is on developing a testing framework for APR vs the UEDT, the full estimation results for all equations are not presented here. Therefore, the impact of the inclusion of the both factors on the key estimated parameters, such as the price and income elasticities, (such as how the inclusion of time dummies impacts on the estimated income elasticity, similar to that shown in Griffin and Schulman, 2005) are not examined here. However, this will be part of future work. Similarly, the diagnostics for all equations are not given for the same reason, but when actually attempting to estimate the key income and price elasticities it is important that the whole range of diagnostic tests are considered in addition to the tests provided here. Nevertheless, it is worth noting that in general, the estimated ARDL equations are generally free of autocorrelation, non-normality etc.
} 
Starting with the time series results, for two out of the 17 countries (Belgium and Japan) the null hypothesis is rejected for both Test 1 and Test 2 for all three specifications. For two countries (Portugal and the USA) ${ }^{19}$ the null hypothesis is unable to be accepted only once whilst for one country (France) the null hypothesis is unable to be accepted only twice (once for Test 1 and once for Test 2). Thus, overall, for this group of counties the time series results suggest that the UEDT and APR are complements.

For four out of the 17 countries (Austria, Canada, Denmark, and the UK) the null hypothesis is always rejected for Test 1 but the null hypothesis is unable to be rejected in all cases for Test 2. For three countries (Ireland, the Netherlands, and Norway), the null hypothesis is unable to be rejected in all cases for Test 2 but the null hypothesis is rejected twice for Test 1 , whereas for another two countries, although the number of tests are limited, there is a similar pattern. For the static versions for Greece, the null hypothesis is rejected for Test 1 but unable to be rejected for Test 2 but for Spain, the null hypothesis is rejected for Test 1 twice but unable to be rejected for Test 2 once. $^{20}$ Thus, overall, for this group of counties the time series results appear to suggest that the UEDT is to be preferred to APR.

For three out of the 17 countries (Italy, Sweden, and Switzerland) ${ }^{21}$ for all tests the null hypothesis is only rejected once (for the static specification); suggesting that neither the UEDT nor APR 'dominate' each other. Hence, for this group of countries the time series results suggest that the UEDT and APR are substitutes.

\footnotetext{
${ }^{19}$ Although it should be noted that for the USA, Test 2 is not estimated for one specification.

${ }^{20}$ Although, given the limited number of tests estimated, the results for Greece and Spain are weaker than the results for the other countries in this second group.

${ }^{21}$ Although it should be noted that for Test 2 two specifications for Sweden are not estimated, and one specification for the Switzerland is not estimated.
} 
The above shows that for the time series results, the countries can be grouped into three groups. For the first group of countries (Belgium, France, Japan, Portugal, and the USA) the UEDT and APR appear to be complements, for the second group (Austria, Canada, Denmark, Greece, Ireland, the Netherlands, Norway, Spain, the UK) the UEDT appears to 'dominate' APR, whereas, for the third group (Italy, Sweden, and Switzerland) the UEDT and APR appear to be substitutes. Turning to the panel data results, the null hypothesis is rejected for Test 1 for all three specifications and the static specification of Test 2. However, the null hypothesis cannot be rejected for the PAM and Koyck specifications for Test 2, suggesting that the UEDT is to be preferred to APR, which, not surprisingly, is consistent with the second (and largest) group indentified above for the time series results.

\section{Concluding remarks}

This paper has developed a statistical framework to determine whether APR and a non-linear UEDT are complements or substitutes when estimating energy demand functions. The tests outlined have been applied to a sample of 17 OECD countries over the period 1960 to 2006 using both single time-series and panel data estimation. When the countries are grouped as a panel (assuming homogeneity of income and price responses across all countries), the tests generally suggest that UEDT 'dominates' APR. The results from the time series tests, however, are mixed. For nine of the 17 counties (Austria, Canada, Denmark, Greece, Ireland, the Netherlands, Norway, Spain, and the UK) the results are consistent with the panel results. Whereas for five of the 17 countries (Belgium, France, Japan, Portugal, and the USA) the UEDT and APR are complements and for three of the 17 countries (Italy, Sweden, and Switzerland) the UEDT and APR appear to be substitutes. 
The implications of these results are that changes in energy prices may well induce asymmetric changes in the derived demand for energy depending upon whether the price falls, rises, or rises above a previous maximum. Equally, the derived demand for energy may well also be driven by exogenous factors such as improvements in the efficiency of the capital and appliance stock, government regulations, socio-economic factors, etc. But not necessarily for all countries. Consequently, it is vital that energy demand modellers should not assume at the outset that one method is superior to the other given the evidence presented here. Moreover, it should be noted that the analysis undertaken here is for total energy, whereas, the focus of much of the previous price decomposition literature focussed on oil (although some other energy sources have since been considered) and when discussing whether technical change is 'energy-using' or 'energy-saving', it should be remembered that energy is by no means a single homogeneous good. Hence, different results concerning the complementarity/substitutability between APR and a UEDT might well be obtained by focusing on different energy sources and it would be interesting to see the suggested tests applied to oil and other fuels. However, the principle of the analysis undertaken here, arguably, applies to any energy source and if energy demand modellers do assume one or other approach then it may well lead to misleading and biased estimates. Therefore, the analysis strongly suggests that when estimating energy or fuel demand functions a general model allowing for APR and UEDT should initially be estimated and only if accepted by the data should a more restrictive specification be considered as the preferred specification.

However, it should be emphasised, that although this agrees with the view of 'letting the data speak', it is equally important that when actually 'searching' for the preferred specification, modellers will still need to ensure that it is well specified. If not, other problems, such as omission of a variable, inappropriate dynamics etc., could be responsible for the test findings. 
Hence, while such problems might be expected to affect tests of both the significance of APR in a model that has UEDT and the significance of UEDT in a model that has APR, there is no reason to expect that both these tests would be affected in the same way. Thus, modellers should also check the diagnostics, conduct a sensitivity analysis, etc. in the normal way to show that the model is well specified and that the findings withstand modifications in lag length, etc. Furthermore, as advocated by Adeyemi and Hunt (2007), there is still also the need to ensure that the preferred models are guided by economic intuition and theory.

Given the results obtained here, further research will apply the testing structure and estimate the 'preferred' energy demand specification for specific groups of countries and/or individual countries, exploring how the inclusion or exclusion of the APR and UEDT as suggested by the tests, impacts on the estimated income and price elasticities. Furthermore, although the results suggest that there is a statistical role for both APR and a UEDT, it is not clear what the relative explanatory power of each is. Further research will therefore also attempt to decompose the contributions from both in order to compare their relative contributions.

In addition, other problems will also be addressed and if possible tested. Several authors, including Ryan and Plourde (2002) and Griffin and Schulman (2005), have identified potential flaws in the price decomposition used here to model asymmetry; in particular the reliance on the old maximum price which is dependent on the starting point of the data. Future work should therefore consider (and preferably test statistically) alternative approaches to decomposing prices (and perhaps income). In addition, the assumption of homogeneity of income and price responses across countries when using panel data is arguably too restrictive (at least as an initial assumption) and a more heterogeneous approach (as the initial general model) should also be considered and tested accordingly. 


\section{Appendix A}

As stated in footnote 6 , given the emphasis in the literature the main text assumes that there is a role to play for at least either APR or a UEDT. This is based on the strong theoretical and conceptual arguments about the derived demand nature of energy and the effect of the technical progress of the appliance and capital stock and other important exogenous influences. However for completeness, included here in symmetric models are individual tests to ascertain whether there is a role to play for A) a UEDT and B) APR separately. Test $A$ is a LR-test for the time series results as illustrated in footnote 12 and an F-test for the panel results as used in Huntington (2006). Whereas, Test B are F-tests as illustrated in footnote 13 for the time series results and as used in Huntington (2006) for the panel results. ${ }^{22}$ The results of the tests are given in Table A1 and show that for the panel data the null hypothesis of no UEDT (Test $A$ ) is always rejected as is the null hypothesis of symmetric price responses (Test $B$ ) - clearly suggesting that both the UEDT and APR have a role to play. For the Test $A$ time series results the null hypothesis of no UEDT is rejected a total of 34 times but is unable to be rejected only 13 times; whereas for Test $B$ the null hypothesis of symmetric price responses is rejected a total of 25 times and is unable to be rejected a total of 26 times. Thus, overall, there appears to be role for both a UEDT and APR.

\section{\{Insert Table A1 about here\}}

\footnotetext{
${ }^{22}$ For consistency with tests in main text, the time series estimation is undertaken in STAMP 6.3 and the panel estimation and tests are undertaken in EViews7.
} 


\section{References}

Adeyemi, O. I., and Hunt, L. C. (2007) Modelling OECD industrial energy demand: asymmetric price responses and energy-saving technical change. Energy Economics, 29, 693-709

Ahmadian, M., Chitnis, M., and Hunt, L. C. (2007) Gasoline demand, pricing policy an social welfare in the Islamic Republic of Iran, The OPEC Review, 31, 105-124

Al-Rabbaie, A. and Hunt, L. C. (2006) OECD energy demand: modelling underlying energy demand trends using the structural time series model. Surrey Energy Economics Discussion Papers, SEEDS No 114 October.

Baade, P. (1981) International energy evaluation system: international energy prices: 1955-1980. Information Administration, US Department of Energy Report, SR/STID/81-21, Washington, DC, December.

Beenstock, M., Willcocks, P. (1981) Energy consumption and economic activity in industrialised countries. Energy Economics, 3, 225-232.

Beenstock, M., Willcocks, P. (1983) Energy and economic activity: a reply to Kouris. Energy Economics, 5, 212

Dargay, J. M. (1992) The Irreversible Effects of High Oil Prices: Empirical Evidence for the Demand for Motor Fuels in France, Germany and the UK in Hawdon, D. (ed.), Energy Demand: Evidence and Expectations, Surrey University Press, Guildford, UK.

Dargay, J. M., Gately, D. (1995a) The imperfect price-reversibility of non-transport oil demand in the OECD. Energy Economics, 17, 59-71.

Dargay, J. M., Gately, D. (1995b) The response of world energy and oil demand to income growth and changes in oil prices. Annual Review of Energy, 20, 145-178.

Dargay, J. M., Gately, D. (1997) The demand for transportation fuels: imperfect price reversibility? Transportation Research B, 31, 71-82.

Dimitropoulos, J., Hunt, L. C. and Judge, G. (2005) Estimating underlying energy demand trends using UK annual data. Applied Economics Letters, 12, 239-244.

EViews 7 (2007) Quantitative Micro Software.

Gately, D. (1993) The Imperfect Price-Reversibility of World Oil Demand. The Energy Journal, 12, 163-182.

Gately, D., Huntington, H. G. (2002) The asymmetric effects of changes in price and income on energy and oil demand. The Energy Journal, 23, 19-55

Griffin J. M., Schulman C. T. (2005) Price asymmetry in energy demand models: A proxy for energy-saving technical change? The Energy Journal, 26, 1-21.

Harvey, A. C. (1989) Forecasting, structural time series models and Kalman filter. Cambridge UK: Cambridge University Press.

Harvey, A. C. (1997) Trends cycles and autoregression. Economic Journal, 107, pp. 192-201. 
Hunt, L. C., Judge, G. and Ninomiya, Y. (2003a) Underlying trends and seasonality in UK energy demand: A sectoral analysis. Energy Economics, 25, 93-118.

Hunt, L. C., Judge, G. and Ninomiya, Y. (2003b) Modelling underlying energy demand trends. Chapter 9 in L. C. Hunt (Ed) Energy in a Competitive Market: Essays in Honour of Colin Robinson, Edward Elgar, UK. 140-174.

Hunt, L. C. and Ninomiya, Y. (2003) Unravelling trends and seasonality: A structural time series analysis of transport oil demand in the UK and Japan. The Energy Journal, 24, 63-96.

Huntington, H. (2006) A note on price asymmetry as induced technical change. The Energy Journal, 27, 1-7.

Koopman S. J., A. C. Harvey, J. A. Doornik and N. Shephard (2000) Stamp: structural time series analyser, modeller and predictor. London: Timberlake Consultants Press.

Kouris, G. (1983a) Fuel consumption for road transport in the USA. Energy Economics, 5, 89-99.

Kouris, G. (1983b) Energy consumption and economic activity in industrialised economies: a note. Energy Economics, 5, 207-212.

Lescaroux, F. and Rech, O. (2008) The impact of automobile diffusion on the income elasticity of motor fuel demand. The Energy Journal, 29, 41-60.

Ryan, D. L. and Plourde, A. (2002) Smaller and smaller? The price responsiveness of nontransport oil demand. Quarterly Review of Economics and Finance, 42, 285-317. 


\section{Figures and Tables}

\section{$\underline{\text { Figure } 1}$}

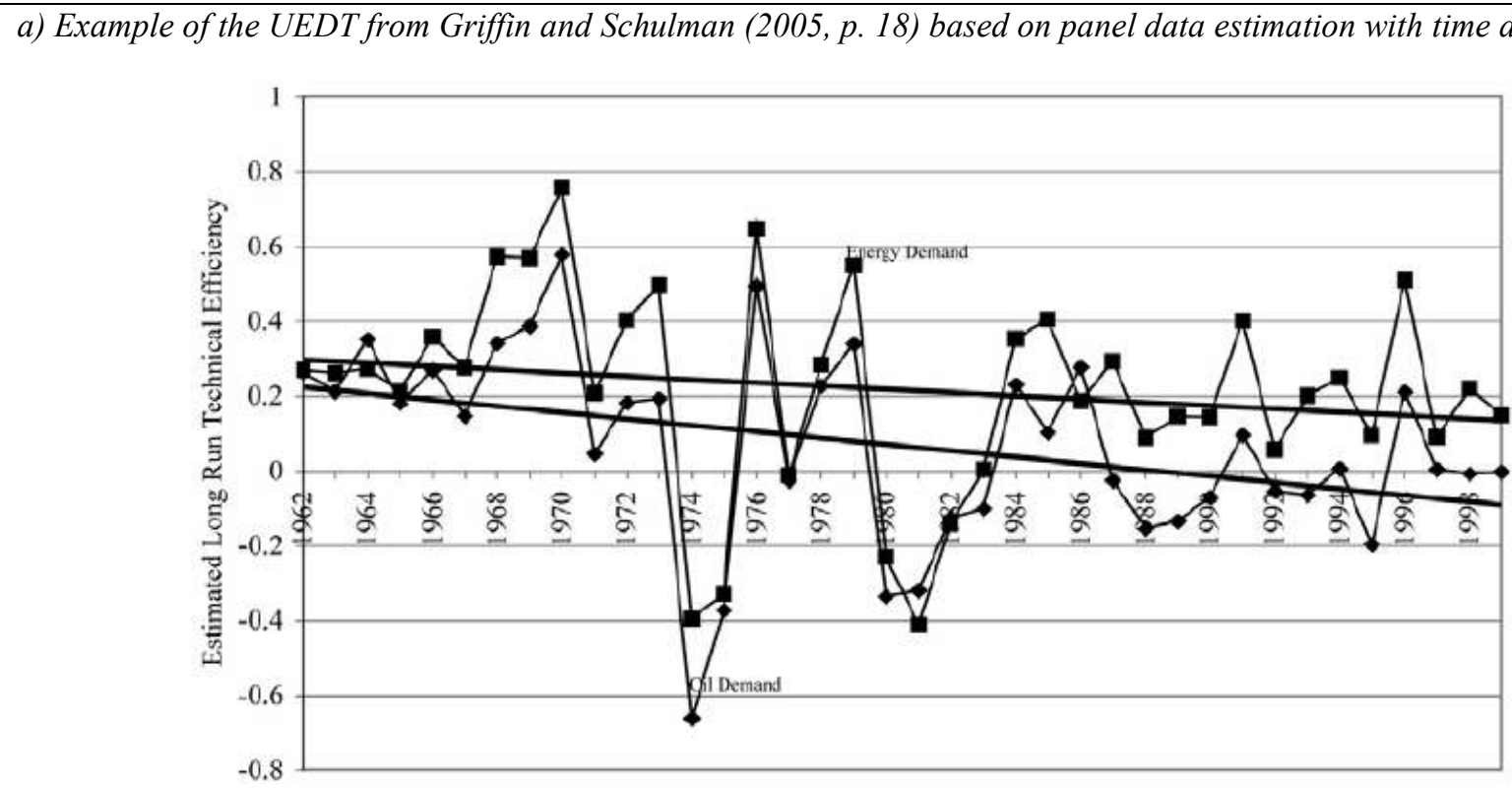

OECD Oil and Energy Demand Trends

b) Example of the UEDT from Dimitropoulos et al. (2005, $p$. 243) based on time series estimation with a stochastic trend.

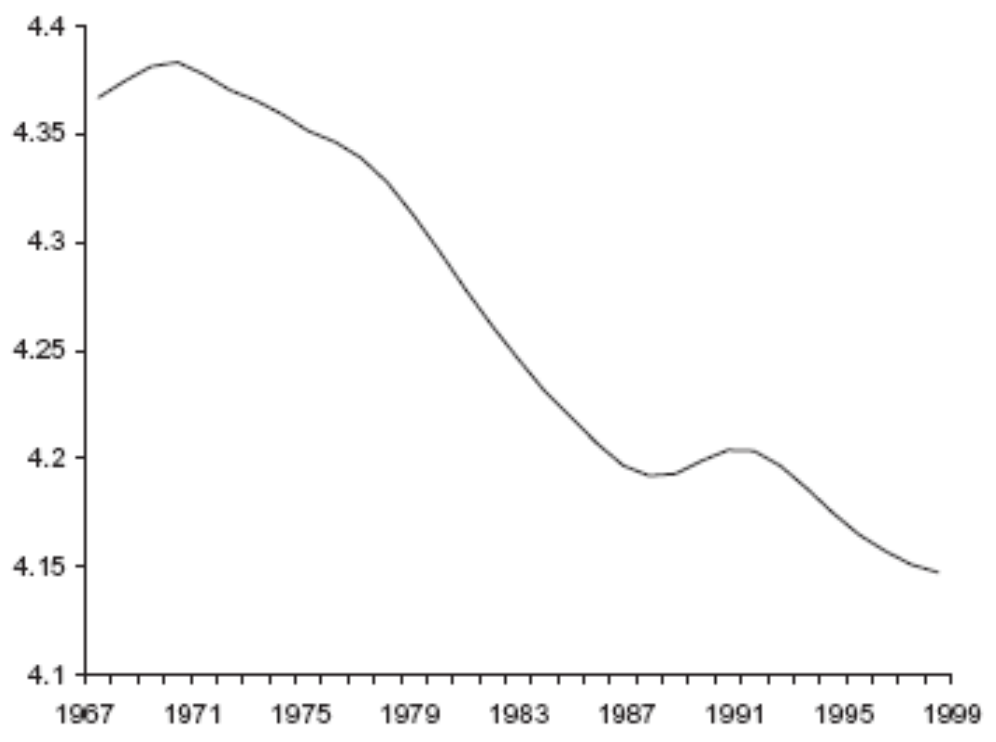

UK Whole Economy Aggregate Energy Demand Trend 


\section{Table 1: Tests in a time-series context}

\begin{tabular}{|c|c|c|}
\hline $\begin{array}{l}\text { Unrestricted models } \\
\text { Static }\end{array}$ & PAM & ARDL \\
\hline $\begin{aligned} e_{t}= & \mu_{t}+\beta^{y} y_{t}+\beta^{m} p_{t}^{m}+\beta^{r} p_{t}^{r}+\beta^{c} p_{t}^{c} \\
& +\varepsilon_{t}\end{aligned}$ & $\begin{aligned} e_{t}= & \mu_{t}+\beta^{y} y_{t}+\beta^{m} p_{t}^{m}+\beta^{r} p_{t}^{r}+\beta^{c} p_{t}^{c} \\
& +\beta^{e 1} e_{t-1}+\varepsilon_{t}\end{aligned}$ & $\begin{aligned} e_{t}= & \mu_{t}+\beta^{y} y_{t}+\beta^{m} p_{t}^{m}+\beta^{r} p_{t}^{r}+\beta^{c} p_{t}^{c} \\
& +\beta^{y 1} y_{t-1}+\beta^{m 1} p_{t-1}^{m}+\beta^{r 1} p_{t-1}^{r}+\beta^{c 1} p_{t-1}^{c} \\
& +\beta^{e 1} e_{t-1}+\varepsilon_{t}\end{aligned}$ \\
\hline \multicolumn{3}{|l|}{ Test 1: $H_{0}: \sigma_{\eta}^{2}=0$} \\
\hline $\begin{array}{l}\text { Restricted models } \\
\text { Static }\end{array}$ & PAM & ARDL \\
\hline $\begin{aligned} e_{t}= & \mu+\beta^{y} y_{t}+\beta^{m} p_{t}^{m}+\beta^{r} p_{t}^{r}+\beta^{c} p_{t}^{c} \\
& +\varepsilon_{t}\end{aligned}$ & $\begin{aligned} e_{t}= & \mu+\beta^{y} y_{t}+\beta^{m} p_{t}^{m}+\beta^{r} p_{t}^{r}+\beta^{c} p_{t}^{c} \\
& +\beta^{e 1} e_{t-1}+\varepsilon_{t}\end{aligned}$ & $\begin{aligned} e_{t}= & \mu+\beta^{y} y_{t}+\beta^{m} p_{t}^{m}+\beta^{r} p_{t}^{r}+\beta^{c} p_{t}^{c} \\
& +\beta^{y 1} y_{t-1}+\beta^{m 1} p_{t-1}^{m}+\beta^{r 1} p_{t-1}^{r}+\beta^{c 1} p_{t-1}^{c} \\
& +\beta^{e 1} e_{t-1}+\varepsilon_{t}\end{aligned}$ \\
\hline \multicolumn{3}{|l|}{ Test 2: $H_{0}: \beta^{m}=\beta^{r}=\beta^{c}=\beta^{p}$} \\
\hline $\begin{array}{l}\text { Restricted models } \\
\text { Static }\end{array}$ & PAM & ARDL \\
\hline$e_{t}=\mu_{t}+\beta^{y} y_{t}+\beta^{p} p_{t}+\varepsilon_{t}$ & $e_{t}=\mu_{t}+\beta^{y} y_{t}+\beta^{p} p_{t}+\beta^{e 1} e_{t-1}+\varepsilon_{t}$ & $\begin{aligned} e_{t}= & \mu_{t}+\beta^{y} y_{t}+\beta^{p} p_{t}+\beta^{y 1} y_{t-1}+\beta^{p 1} p_{t-1} \\
& +\beta^{e 1} e_{t-1}+\varepsilon_{t}\end{aligned}$ \\
\hline
\end{tabular}




\section{Table 2: Tests in a panel data context}

\begin{tabular}{|c|c|c|}
\hline $\begin{array}{l}\text { Unrestricted models } \\
\text { Static }\end{array}$ & PAM & Koyck \\
\hline $\begin{aligned} e_{t i}= & \beta+\beta^{y} y_{i t}+\beta^{m} p_{i t}^{m}+\beta^{r} p_{i t}^{r}+\beta^{c} p_{i t}^{c} \\
& +\delta_{i} D_{i}+\theta_{t} D_{t}+\varepsilon_{i t}\end{aligned}$ & $\begin{aligned} e_{t i}= & \beta+\beta^{y} y_{i t}+\beta^{m} p_{i t}^{m}+\beta^{r} p_{i t}^{r}+\beta^{c} p_{i t}^{c} \\
& +\beta^{e 1} e_{i t-1}+\delta_{i} D_{i}+\theta_{t} D_{t}+\varepsilon_{t i}\end{aligned}$ & $\begin{aligned} e_{i t}= & \beta+\beta^{y}\left(y_{i t}-\beta^{e 1} y_{i t-1}\right)+\beta^{m} p_{i t}^{m} \\
& +\beta^{r} p_{i t}^{r}+\beta^{c} p_{i t}^{c}+\beta^{e 1} e_{i t-1} \\
& +\delta_{i} D_{i}+\theta_{t} D_{t}+\varepsilon_{t i}\end{aligned}$ \\
\hline \multicolumn{3}{|l|}{ Test 1: $H_{0}: \theta_{t}=0$} \\
\hline $\begin{array}{l}\text { Restricted models } \\
\text { Static }\end{array}$ & PAM & Koyck \\
\hline $\begin{aligned} e_{t i}= & \beta+\beta^{y} y_{i t}+\beta^{m} p_{i t}^{m}+\beta^{r} p_{i t}^{r}+\beta^{c} p_{i t}^{c} \\
& +\delta_{i} D_{i}++\varepsilon_{i t}\end{aligned}$ & $\begin{aligned} e_{t i}= & \beta+\beta^{y} y_{i t}+\beta^{m} p_{i t}^{m}+\beta^{r} p_{i t}^{r}+\beta^{c} p_{i t}^{c} \\
& +\beta^{e 1} e_{i t-1}+\delta_{i} D_{i}+\varepsilon_{t i}\end{aligned}$ & $\begin{aligned} e_{i t}= & \beta+\beta^{y}\left(y_{i t}-\beta^{e 1} y_{i t-1}\right)+\beta^{m} p_{i t}^{m} \\
& +\beta^{r} p_{i t}^{r}+\beta^{c} p_{i t}^{c}+\beta^{e 1} e_{i t-1} \\
& +\delta_{i} D_{i}+\varepsilon_{t i} \quad \text { (7c) }\end{aligned}$ \\
\hline \multicolumn{3}{|l|}{ Test 2: $H_{0}: \beta^{m}=\beta^{r}=\beta^{c}=\beta^{p}$} \\
\hline $\begin{array}{l}\text { Restricted models } \\
\text { Static }\end{array}$ & PAM & Koyck \\
\hline $\begin{aligned} e_{t i}= & \beta+\beta^{y} y_{i t}+\beta^{p} p_{i t}+\delta_{i} D_{i} \\
& +\theta_{t} D_{t}+\varepsilon_{i t}\end{aligned}$ & $\begin{aligned} e_{t i}= & \beta+\beta^{y} y_{i t}+\beta^{p} p_{i t}+\beta^{e 1} e_{i t-1} \\
& +\delta_{i} D_{i}+\theta_{t} D_{t}+\varepsilon_{i t}\end{aligned}$ & $\begin{aligned} e_{i t}= & \beta+\beta^{y}\left(y_{i t}-\beta^{e 1} y_{i t-1}\right)+\beta^{p} p_{i t} \\
& +\beta^{e 1} e_{i t-1}+\delta_{i} D_{i} \\
& +\theta_{t} D_{t}+\varepsilon_{t i}\end{aligned}$ \\
\hline
\end{tabular}




\section{Table 3: Test Results}

\section{Time series results}

\begin{tabular}{|c|c|c|c|c|c|c|c|}
\hline ( & & Static & PAM & ARDL & Static & PAM & ARDL \\
\hline \multirow[t]{2}{*}{ Austria } & Test 1 & 0.000 & 0.009 & 0.019 & X & X & $\mathrm{X}$ \\
\hline & Test 2 & 0.604 & 0.612 & 0.613 & $\sqrt{ }$ & $\sqrt{ }$ & $\sqrt{ }$ \\
\hline \multirow[t]{2}{*}{ Belgium } & Test 1 & 0.000 & 0.007 & 0.005 & $X$ & $\mathrm{X}$ & $\mathrm{X}$ \\
\hline & Test 2 & 0.008 & 0.006 & 0.020 & $X$ & $X$ & $X$ \\
\hline \multirow[t]{2}{*}{ Canada } & Test 1 & 0.000 & 0.002 & 0.002 & $x$ & $x$ & $x$ \\
\hline & Test 2 & 0.540 & 0.501 & 0.582 & $\sqrt{ }$ & $\sqrt{ }$ & $\sqrt{ }$ \\
\hline \multirow{2}{*}{ Denmark } & Test 1 & 0.000 & 0.000 & 0.037 & $x$ & $x$ & $x$ \\
\hline & Test 2 & 0.874 & 0.947 & 0.142 & $\sqrt{ }$ & $\sqrt{ }$ & $\sqrt{ }$ \\
\hline \multirow[t]{2}{*}{ France } & Test 1 & 0.000 & 0.034 & 0.151 & $x$ & $x$ & $\sqrt{ }$ \\
\hline & Test 2 & 0.023 & 0.033 & 0.109 & $X$ & $\mathrm{X}$ & $\sqrt{ }$ \\
\hline \multirow[t]{2}{*}{ Greece } & Test 1 & 0.000 & $\mathrm{n} / \mathrm{a}$ & $\mathrm{n} / \mathrm{a}$ & 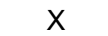 & - & - \\
\hline & Test 2 & 0.196 & $\mathrm{n} / \mathrm{a}$ & $\mathrm{n} / \mathrm{a}$ & $\sqrt{ }$ & - & - \\
\hline \multirow[t]{2}{*}{ Ireland } & Test 1 & 0.000 & 0.084 & 0.010 & $x$ & $\sqrt{ }$ & $x$ \\
\hline & Test 2 & 0.797 & 0.952 & 0.969 & $\sqrt{ }$ & $\sqrt{ }$ & $\sqrt{ }$ \\
\hline \multirow[t]{2}{*}{ Italy } & Test 1 & 0.000 & 0.295 & 0.559 & $x$ & $\sqrt{ }$ & $\sqrt{ }$ \\
\hline & Test 2 & 0.971 & 0.641 & 0.176 & $\sqrt{ }$ & $\sqrt{ }$ & $\sqrt{ }$ \\
\hline \multirow[t]{2}{*}{ Japan } & Test 1 & 0.000 & 0.018 & 0.007 & $x$ & $X$ & $x$ \\
\hline & Test 2 & 0.007 & 0.017 & 0.037 & $x$ & $x$ & $x$ \\
\hline \multirow[t]{2}{*}{ Netherlands } & Test 1 & 0.000 & 0.007 & 0.201 & $x$ & $x$ & $\sqrt{ }$ \\
\hline & Test 2 & 0.085 & 0.279 & 0.998 & $\sqrt{ }$ & $\sqrt{ }$ & $\sqrt{ }$ \\
\hline \multirow[t]{2}{*}{ Norway } & Test 1 & 0.000 & 0.030 & 0.072 & $x$ & $x$ & $\sqrt{ }$ \\
\hline & Test 2 & 0.482 & 0.467 & 0.584 & $\sqrt{ }$ & $\sqrt{ }$ & $\sqrt{ }$ \\
\hline \multirow[t]{2}{*}{ Portugal } & Test 1 & 0.000 & 0.000 & 0.003 & $x$ & $x$ & $x$ \\
\hline & Test 2 & 0.000 & 0.005 & 0.074 & $x$ & $x$ & $\sqrt{ }$ \\
\hline \multirow[t]{2}{*}{ Spain } & Test 1 & 0.000 & 0.094 & 0.043 & $x$ & $\sqrt{ }$ & $x$ \\
\hline & Test 2 & $\mathrm{n} / \mathrm{a}$ & $\mathrm{n} / \mathrm{a}$ & 0.906 & - & - & $\sqrt{ }$ \\
\hline \multirow[t]{2}{*}{ Sweden } & Test 1 & 0.000 & 0.141 & 0.115 & $x$ & $\sqrt{ }$ & $\sqrt{ }$ \\
\hline & Test 2 & 0.296 & $\mathrm{n} / \mathrm{a}$ & $\mathrm{n} / \mathrm{a}$ & $\sqrt{ }$ & - & - \\
\hline \multirow[t]{2}{*}{ Switzerland } & Test 1 & 0.000 & 0.054 & 0.920 & $x$ & $\sqrt{ }$ & $\sqrt{ }$ \\
\hline & Test 2 & 0.379 & 0.434 & $\mathrm{n} / \mathrm{a}$ & $\sqrt{ }$ & $\sqrt{ }$ & - \\
\hline \multirow[t]{2}{*}{ UK } & Test 1 & 0.000 & 0.000 & 0.002 & $x$ & $x$ & $x$ \\
\hline & Test 2 & 0.314 & 0.454 & 0.456 & $\sqrt{ }$ & $\sqrt{ }$ & $\sqrt{ }$ \\
\hline \multirow[t]{2}{*}{ USA } & Test 1 & 0.000 & 0.012 & 0.061 & $x$ & $x$ & $\sqrt{ }$ \\
\hline & Test 2 & 0.014 & 0.029 & $\mathrm{n} / \mathrm{a}$ & $x$ & $x$ & - \\
\hline & & Static & PAM & Koyck & Static & PAM & Koyck \\
\hline & Test 1 & 0.000 & 0.000 & 0.000 & $x$ & $x$ & x \\
\hline & Test 2 & 0.000 & 0.208 & 0.236 & $x$ & $\sqrt{ }$ & $\sqrt{ }$ \\
\hline
\end{tabular}

Panel Results

Note: Test $1 H_{0}: \sigma_{\eta}^{2}=0$, for time series data; $\theta_{t}=0$, for panel data - with APR maintained.

Test $2 H_{0}: \beta^{m}=\beta^{r}=\beta^{c}=\beta^{p}$, for time series and panel data - with UEDT maintained)

Numbers refer to the $p$-values for the tests outlined in the text

$X$ shows that the null hypothesis is rejected at the $5 \%$ level of significance

$\sqrt{ }$ shows that the null hypothesis cannot be rejected at the $5 \%$ level of significance $\mathrm{n} / \mathrm{a}=$ not estimated given $\sigma_{\eta}^{2}=0$, non-convergence, or local maximum obtained 
Table A1: Test Results

\begin{tabular}{|c|c|c|c|c|c|c|c|}
\hline \multicolumn{8}{|l|}{ Time series results } \\
\hline \multirow[t]{2}{*}{ Austria } & Test $A$ & 0.000 & 0.007 & 0.012 & $x$ & $x$ & $x$ \\
\hline & Test $B$ & 0.000 & 0.090 & 0.131 & $x$ & $\sqrt{ }$ & $\sqrt{ }$ \\
\hline \multirow[t]{2}{*}{ Belgium } & Test A & 0.000 & 0.014 & 0.121 & $\mathrm{X}$ & $\mathrm{X}$ & $\sqrt{ }$ \\
\hline & Test $B$ & 0.000 & 0.009 & 0.097 & $x$ & $x$ & $\sqrt{ }$ \\
\hline \multirow[t]{2}{*}{ Canada } & Test $A$ & 0.000 & 0.000 & 0.007 & $x$ & $x$ & $X$ \\
\hline & Test $B$ & 0.000 & 0.032 & 0.542 & $x$ & $x$ & $\sqrt{ }$ \\
\hline \multirow[t]{2}{*}{ Denmark } & Test $A$ & 0.000 & 0.001 & 0.287 & $\mathrm{X}$ & $X$ & $\sqrt{ }$ \\
\hline & Test $B$ & 0.000 & 0.615 & 0.191 & $x$ & $\sqrt{ }$ & $\sqrt{ }$ \\
\hline \multirow[t]{2}{*}{ France } & Test $A$ & 0.000 & 0.007 & 0.047 & $\mathrm{X}$ & $\mathrm{X}$ & $\mathrm{X}$ \\
\hline & Test $B$ & 0.000 & 0.003 & 0.015 & $\mathrm{X}$ & $x$ & $\mathrm{X}$ \\
\hline \multirow[t]{2}{*}{ Greece } & Test $A$ & 0.000 & 0.062 & 0.186 & $\mathrm{X}$ & $\sqrt{ }$ & $\sqrt{ }$ \\
\hline & Test $B$ & 0.000 & 0.028 & 0.162 & $x$ & $\mathrm{X}$ & $\sqrt{ }$ \\
\hline \multirow[t]{2}{*}{ Ireland } & Test $A$ & 0.000 & 0.033 & 0.001 & $\mathrm{X}$ & $X$ & $x$ \\
\hline & Test $B$ & 0.000 & 0.118 & 0.166 & $X$ & $\sqrt{ }$ & $\sqrt{ }$ \\
\hline \multirow[t]{2}{*}{ Italy } & Test $A$ & 0.000 & 0.008 & 0.008 & $\mathrm{X}$ & $\mathrm{X}$ & $\mathrm{X}$ \\
\hline & Test $B$ & 0.488 & 0.014 & 0.024 & $\sqrt{ }$ & $X$ & $\mathrm{X}$ \\
\hline \multirow[t]{2}{*}{ Japan } & Test $A$ & 0.000 & 0.000 & 0.401 & $\mathrm{X}$ & X & $\sqrt{ }$ \\
\hline & Test $B$ & 0.000 & 0.000 & 0.042 & $\mathrm{x}$ & $\mathrm{x}$ & $x$ \\
\hline \multirow[t]{2}{*}{ Netherlands } & Test $A$ & 0.000 & 0.302 & 0.697 & $x$ & $\sqrt{ }$ & $\sqrt{ }$ \\
\hline & Test $B$ & 0.065 & 0.672 & 0.186 & $\sqrt{ }$ & $\sqrt{ }$ & $\sqrt{ }$ \\
\hline \multirow[t]{2}{*}{ Norway } & Test $A$ & 0.000 & 0.057 & 0.372 & $\mathrm{X}$ & $\sqrt{ }$ & $\sqrt{ }$ \\
\hline & Test $B$ & 0.783 & 0.324 & 0.632 & $\sqrt{ }$ & $\sqrt{ }$ & $\sqrt{ }$ \\
\hline \multirow[t]{2}{*}{ Portugal } & Test $A$ & 0.000 & 0.000 & 0.094 & $\mathrm{x}$ & $x$ & $\sqrt{ }$ \\
\hline & Test $B$ & 0.000 & 0.001 & 0.216 & $X$ & $x$ & $\sqrt{ }$ \\
\hline \multirow[t]{2}{*}{ Spain } & Test A & 0.000 & 0.209 & 0.235 & $\mathrm{X}$ & $\sqrt{ }$ & $\sqrt{ }$ \\
\hline & Test $B$ & 0.000 & 0.919 & 0.889 & $x$ & $\sqrt{ }$ & $\sqrt{ }$ \\
\hline \multirow[t]{2}{*}{ Sweden } & Test $A$ & 0.000 & $\mathrm{n} / \mathrm{a}$ & $\mathrm{n} / \mathrm{a}$ & $\mathrm{X}$ & - & - \\
\hline & Test B & 0.001 & 0.312 & 0.247 & $X$ & $\sqrt{ }$ & $\sqrt{ }$ \\
\hline \multirow[t]{2}{*}{ Switzerland } & Test $A$ & 0.000 & 0.074 & $\mathrm{n} / \mathrm{a}$ & $\mathrm{X}$ & $\sqrt{ }$ & - \\
\hline & Test $B$ & 0.000 & 0.066 & 0.132 & $x$ & $\sqrt{ }$ & $\sqrt{ }$ \\
\hline \multirow[t]{2}{*}{ UK } & Test $A$ & 0.000 & 0.002 & 0.026 & $\mathrm{X}$ & $x$ & $X$ \\
\hline & Test $B$ & 0.019 & 0.862 & 0.700 & $\mathrm{X}$ & $\sqrt{ }$ & $\sqrt{ }$ \\
\hline \multirow[t]{2}{*}{ USA } & Test $A$ & 0.000 & 0.000 & $\mathrm{n} / \mathrm{a}$ & $\mathrm{X}$ & $X$ & - \\
\hline & Test $B$ & 0.000 & 0.000 & 0.770 & $\mathrm{X}$ & $x$ & $\sqrt{ }$ \\
\hline \multicolumn{8}{|l|}{ Panel Results } \\
\hline & & Static & PAM & Koyck & Static & PAM & Koyck \\
\hline & Test $A$ & 0.000 & 0.000 & 0.000 & X & $x$ & $\mathrm{X}$ \\
\hline & Test $B$ & 0.000 & 0.000 & 0.002 & $\mathrm{X}$ & $x$ & $x$ \\
\hline
\end{tabular}

Note: Test $A H_{0}: \sigma_{\eta}^{2}=0$, for time series data; $\theta_{t}=0$, for panel data - with symmetry maintained (i.e. without APR).

Test $B H_{0}: \beta^{m}=\beta^{r}=\beta^{c}=\beta^{p}$, for time series and panel data - with no exogenous term maintained (i.e. without UEDT).

Numbers refer to the $p$-values for the tests outlined in the text

$X$ shows that the null hypothesis is rejected at the $5 \%$ level of significance

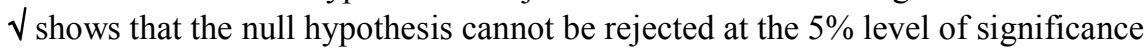

$\mathrm{n} / \mathrm{a}=$ not estimated given $\sigma_{\eta}^{2}=0$, non-convergence, or local maximum obtained 